\title{
Power System Controlled Islanding using Modified Discrete Optimization Techniques
}

\author{
N.Z. Saharuddin ${ }^{1}$ \\ Faculty of Electrical Engineering \\ Universiti Teknikal Malaysia Melaka \\ Melaka, Malaysia
}

\author{
I. Z. Abidin ${ }^{2}$ \\ Department of Electrical and Electronics Engineering \\ Universiti Tenaga Nasional \\ Selangor, Malaysia
}

\author{
H. Mokhlis ${ }^{3}$ \\ Department of Electrical Engineering \\ Universiti Malaya \\ Kuala Lumpur, Malaysia \\ M.Y. Hassan ${ }^{4}$ \\ Department of Electrical Engineering \\ Universiti Teknologi Malaysia \\ Johor, Malaysia
}

\begin{abstract}
Controlled islanding is implemented to save the power system from experiencing blackouts during severe sequence line tripping. The power system is partitioned into several stand-alone islands by removing the optimal transmission line during controlled islanding execution. Since selecting the optimal transmission lines to be removed (cutsets) is important in this action, a good technique is required in order to determine the optimal islanding solution (lines to be removed). Thus, this paper developed two techniques, namely Modified Discrete Evolutionary Programming (MDEP) and Modified Discrete Particle Swarm Optimization (MDPSO) to determine the optimal islanding solution for controlled islanding implementation. The best technique among these two which is based on their capability of producing the optimal islanding solution with minimal objective function (minimal power flow disruption) will be selected to implement the controlled islanding. The performance of these techniques is evaluated through case studies using the IEEE 118-bus test system. The results show that the MDEP technique produces the best optimal islanding solution compared to the MDPSO and other previously published techniques.
\end{abstract}

Keywords-Controlled islanding; modified discrete evolutionary programming (MDEP) technique; modified discrete particle swarm optimization (MDPSO) technique; minimal power flow disruption; power imbalance

\section{INTRODUCTION}

Cascading failures that occur due to severe transmission line outages is the main contribution to power system blackout. This cascading event causes the system to form few unstable islands (unintentional islanding) that finally lead the system to lose its stability and experience a blackout. According to the blackout cases happened around the world, cascading failures is the main reason for the blackout occurrence [1]-[2]. Therefore, prevention on cascading failures which causes the unintentional islanding is important in order to save the system from total collapse. Therefore, controlled islanding is implemented for this purpose. Generally, controlled islanding is executed by disconnecting the selected islanding cutsets in order to forms few stable stand-alone islands. These standalone islands are capable to operate independently and generate electrical power to consumers until the system back to its normal operating condition. The selected islanding cutsets must be optimal and do not cause the system to face any other instability issue after islanding implementation. However, the selection of optimal islanding cutsets is complicated as the search space of possible islanding cutsets is huge and increase proportionally when the system size increased.

Numerous methods on controlled islanding have been proposed by previous researches in recent years [3]. Ordered Binary Decision Diagrams (OBDD) is one of the methods proposed to determine the proper islanding strategy for a power system network [4]-[5]. This method simplifies the huge possible islanding solution using node simplification technique. Another method namely slow coherency approach was proposed to find the suitable islanding cutsets by determining the weakest connection in the network [6]. This method further used in [7] which considers minimal number of line removed with minimal power flow and graph partitioning technique in [8]. Author in [9] further proposed the slow coherency with blackstart unit in each island formed during controlled islanding. Through this, the load and generation balance in each island can be achieved and restoration action can be planned if required. A linear programming technique namely mixed integer linear programming (MILP) which uses DC power flow equation is proposed in islanding cutsets determination in [10]. This method further improved using AC power flow in [11] for better feasible islanding solution determination. Another MILP technique for controlled islanding considering coherent groups of generators is then proposed in [12]. A Heuristic technique which utilizes the possible search technique to determine the best islanding solution is proposed in [13]. Other techniques, which are the meta-heuristic techniques for intentional islanding are proposed by authors in [14]-[15]. These techniques use BPSO [14] and AMPSO [15] to determine the optimal islanding solution using minimal power imbalance as their objective function. Another meta-heuristic technique is proposed in [16] which uses Tabu Search algorithm to determine the islanding solution using similar objective function as in [14],[15]. 
Since determining the optimal islanding cutsets is imperative in controlled islanding, two discrete optimization techniques which are Modified Discrete Evolutionary Programming (MDEP) and Modified Discrete Particle Swarm Optimization (MDPSO) are developed and analysed in this paper. Minimal power flow disruption is used as the objective function in these techniques. The usage of this objective function helps to enhance the transient stability in each island by reducing the power flow change during islanding implementation [17]. The utilization of discrete optimization technique in this work is in line with islanding problem which is discrete in nature. This is because the selection of optimal islanding cutsets (line to be removed) involved with discrete value such as line 2-8, line 9-11 and line 12-13. The main objective of this paper is to select the best technique among the two developed techniques for controlled islanding determination.

\section{DeVEloped TeChNiQues}

In this paper, two different techniques, namely Modified Discrete Evolutionary Programming (MDEP) and Modified Discrete Particle Swarm Optimization (MDPSO) were developed and analysed for controlled islanding determination. The aim of this paper is to select the best technique that capable to find the optimal islanding solution with minimal power flow disruptions.

There are four main stages involved in this work. In stage 1 , the power system network is modelled using the graph theory approach. This approach is vital to identify the transmission line connection during controlled islanding execution. Since the search space for possible islanding solution is huge, an appropriate initial solution is required in order to helps the discrete optimization techniques to find the optimal islanding solution. As such, suitable initial solution for controlled islanding is obtained using initialization based graph theory approach in stage 2 . This initial solution is determined based on the specified constraints which are: i) number of the islands formed, and ii) coherent groups of generator. In this approach, the same coherent generators are grouped together and the numbers of total islands are represented by the total number of generators group. Next, the nearest adjacent nodes (next node) are grouped to the nearest coherent group and the process is continued until all line are assigned to their appropriate coherent groups. The initial cutsets are the line that located between the different coherent generator groups. Further explanation on the implementation of this approach can be found in [18].

In stage 3, the initial solution is then used to assist the discrete optimization techniques in determining the optimal islanding solution. The best technique which capable of determining better optimal islanding solution is identified and controlled islanding is further executed. Then, the loadgeneration balance checking procedure will be performed on each island after intentional islanding execution. This checking is important in order to ensure that each island formed is balanced and capable to operate as a stand-alone island. In the case of any imbalance is detected, the load shedding scheme will be activated in stage 4 . The voltage magnitude at each bus and the power flow at each line in all islands are checked and verified to ensure the voltage limit and line capacity is not violated. Fig. 1 shows the stages involved in the proposed technique.

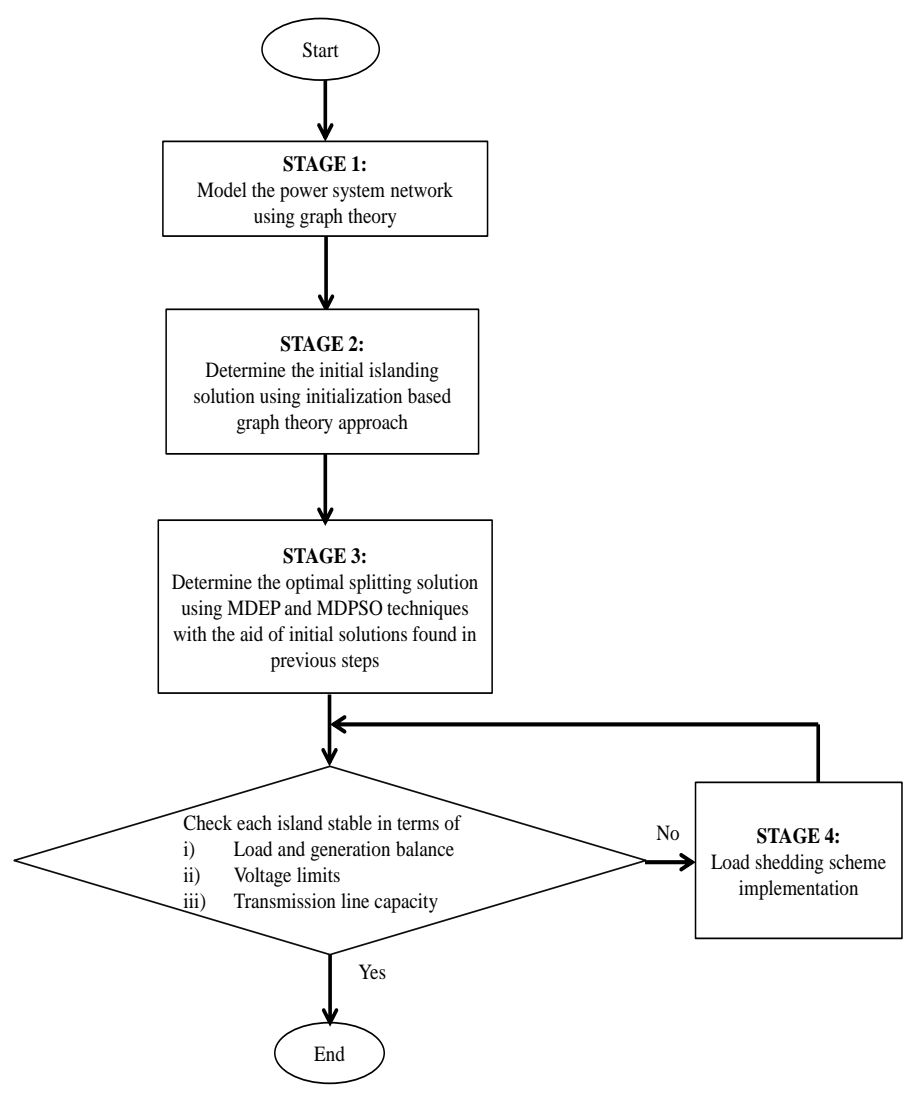

Fig. 1. Flowchart of the Proposed Techqniue.

\section{MethodOLOGY}

Controlled islanding is a discrete problem and the islanding solution is represented by the integer numbers such as line 3-6, 8-9, 10-13 and 11-15. Therefore, the modified discrete optimization technique is utilized in this work. Two different modified discrete optimization techniques (MDEP and MDPSO) are developed in this work in order to determine the optimal islanding solution. This section describes the methodology adopted to develop the two controlled islanding techniques to obtain the optimal islanding solution.

\section{A. Modified Discrete Evolutionary Programming (MDEP)}

The Modified Discrete Evolutionary Programming (MDEP) is developed as one of the controlled islanding technique. The process involved in determining the optimal islanding solution using the MDEP technique is illustrated by the flowchart shown in Fig. 2.

Based on Fig. 2, the initial solution obtained from graph theory approach is used as the initial populations (parents), $x_{i}$ in the MDEP technique. The objective function (minimal power flow disruption) is then calculated using the equation below:

$\min \left\{g(x)=\left(\sum_{a=1}^{a_{\text {line }}}\left|P_{a}\right|\right)\right\}$ 

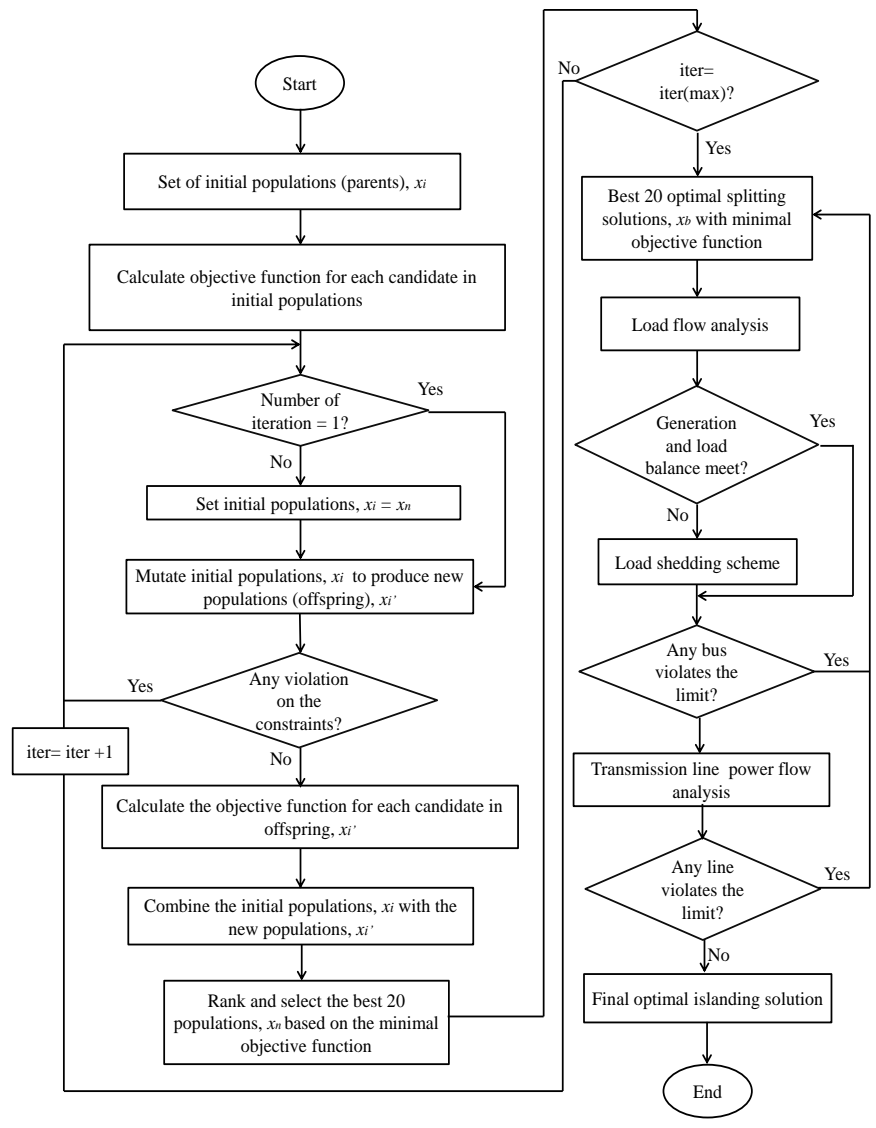

Fig. 2. MDEP Optimization Technique.

where $P_{a}$ is the active power flow in the transmission line (cutsets candidate), and $\mathrm{a}_{\text {line }}$ is the total number of cutsets that disconnected to forms the islands.

Then, the mutation process starts by mutating the initial populations, $x_{i}$ to produce the new populations (offsprings), $x_{i}$ using three different techniques. In the first technique, the mutation is carried out by mutating each cutset in a diagonal form, randomly from the possible transmission lines, $\mathrm{S}_{\mathrm{T}}$ as shown in Table I. The possible transmission lines, $S_{\mathrm{T}}$ is the total number of transmission line, $T L=\left\{T L_{p}\right\}$ in the system where $p=1,2,3 \ldots$.total number of lines.

TABLE I. MutATION Process OF MDEP TeChNIQUe IN TECHNIQUe 1

\begin{tabular}{|l|l|l|l|l|l|l|l|l|}
\hline & $\begin{array}{l}\text { Initial cutsets from } \\
\text { graph theory approach }\end{array}$ & $\mathrm{Z}_{1}$ & $\mathrm{Z}_{2}$ & $\mathbf{Z}_{3}$ & $\mathbf{Z}_{4}$ & $\mathbf{Z}_{5}$ & $\mathbf{Z}_{6}$ & $\mathbf{Z}_{\mathbf{n}}$ \\
\hline 1 & $\begin{array}{l}1^{\text {st }} \text { cutset is randomly } \\
\text { changed }\end{array}$ & $\mathbf{a}_{\mathbf{i} 1}$ & $\mathrm{Z}_{2}$ & $\mathrm{X}_{3}$ & $\mathrm{Z}_{4}$ & $\mathrm{Z}_{5}$ & $\mathrm{Z}_{6}$ & $\mathrm{Z}_{\mathrm{n}}$ \\
\hline 2 & $\begin{array}{l}2^{\text {nd }} \text { cutset is randomly } \\
\text { changed }\end{array}$ & $\mathrm{Z}_{1}$ & $\mathbf{a}_{\mathrm{i} 2}$ & $\mathrm{X}_{3}$ & $\mathrm{Z}_{4}$ & $\mathrm{Z}_{5}$ & $\mathrm{Z}_{6}$ & $\mathrm{Z}_{\mathrm{n}}$ \\
\hline 3 & $\begin{array}{l}3^{\text {rd }} \text { cutset is randomly } \\
\text { changed }\end{array}$ & $\mathrm{Z}_{1}$ & $\mathrm{Z}_{2}$ & $\mathbf{a}_{\mathrm{i} 3}$ & $\mathrm{Z}_{4}$ & $\mathrm{Z}_{5}$ & $\mathrm{Z}_{6}$ & $\mathrm{Z}_{\mathrm{n}}$ \\
\hline 4 & $\begin{array}{l}4^{\text {th }} \text { cutset is randomly } \\
\text { changed }\end{array}$ & $\mathrm{Z}_{1}$ & $\mathrm{Z}_{2}$ & $\mathrm{X}_{3}$ & $\mathbf{a}_{\mathbf{i} 4}$ & $\mathrm{Z}_{5}$ & $\mathrm{Z}_{6}$ & $\mathrm{Z}_{\mathrm{n}}$ \\
\hline 5 & $\begin{array}{l}5^{\text {th }} \text { cutset is randomly } \\
\text { changed }\end{array}$ & $\mathrm{Z}_{1}$ & $\mathrm{Z}_{2}$ & $\mathrm{X}_{3}$ & $\mathrm{Z}_{4}$ & $\mathbf{a}_{\mathrm{i} 5}$ & $\mathrm{Z}_{6}$ & $\mathrm{Z}_{\mathrm{n}}$ \\
\hline 6 & $\begin{array}{l}6^{\text {th }} \text { cutset is randomly } \\
\text { changed }\end{array}$ & $\mathrm{Z}_{1}$ & $\mathrm{Z}_{2}$ & $\mathrm{X}_{3}$ & $\mathrm{Z}_{4}$ & $\mathrm{Z}_{5}$ & $\mathbf{a}_{\mathbf{i 6}}$ & $\mathrm{Z}_{\mathrm{n}}$ \\
\hline 7 & $\begin{array}{l}\mathrm{n}^{\text {th }} \text { cutset is randomly } \\
\text { changed }\end{array}$ & $\mathrm{Z}_{1}$ & $\mathrm{Z}_{2}$ & $\mathrm{X}_{3}$ & $\mathrm{Z}_{4}$ & $\mathrm{Z}_{5}$ & $\mathrm{Z}_{6}$ & $\mathbf{a}_{\mathrm{in}}$ \\
\hline
\end{tabular}

According to Table I, each cutset from the initial solution $\left(Z_{1}, Z_{2} \ldots Z_{n}\right)$ which is obtained from the graph theory approach is mutated and replaced by a random value, $a_{i n}$. For example, if the initial solution contains seven cutsets, the mutation process in technique 1 will produce another new seven mutated islanding solution.

Taking into consideration that the initial solution might produce better optimal islanding solution with less or more number of cutsets, technique 2 and technique 3 are performed as shown in Table II and Table III.

Once the mutation process involving the three techniques completed, the total new populations (mutated islanding solution) obtained from the mutation process above will undergo the constraints checking (desired number of islands and coherent groups of generators). Next, the objective function for each candidate in the new populations is calculated and stored. Then, the combination of the new populations with the initial populations is carried out and the best 20 populations, $x_{n}$ with minimal objective function are ranked and selected for the next iteration. The process continues until it reached the maximum number of iteration specified. Finally, the 20 final best solutions, $x_{b}$ with minimal power flow disruptions are selected as the best possible islanding solution.

TABLE II. Mutation Process of MDEP TeChNIQUE In TECHNIQUe 2

\begin{tabular}{|l|l|l|l|l|l|l|l|l|}
\hline & $\begin{array}{l}\text { Initial cutsets from } \\
\text { graph theory approach }\end{array}$ & $\mathbf{Z}_{\mathbf{1}}$ & $\mathbf{Z}_{\mathbf{2}}$ & $\mathbf{Z}_{\mathbf{3}}$ & $\mathbf{Z}_{\mathbf{4}}$ & $\mathbf{Z}_{\mathbf{5}}$ & $\mathbf{Z}_{\mathbf{6}}$ & $\mathbf{Z}_{\mathbf{n}}$ \\
\hline 1 & $\begin{array}{l}1^{\text {st }} \text { cutset is randomly } \\
\text { changed }\end{array}$ & $\mathbf{a}_{\mathbf{i 1}}$ & $\mathrm{Z}_{2}$ & $\mathrm{Z}_{3}$ & $\mathrm{Z}_{4}$ & $\mathrm{Z}_{5}$ & $\mathrm{Z}_{6}$ & 0 \\
\hline 2 & $\begin{array}{l}2^{\text {nd }} \text { cutset is randomly } \\
\text { changed }\end{array}$ & $\mathrm{Z}_{1}$ & $\mathbf{a}_{\mathbf{i} 2}$ & $\mathrm{Z}_{3}$ & $\mathrm{Z}_{4}$ & $\mathrm{Z}_{5}$ & $\mathrm{Z}_{6}$ & 0 \\
\hline 3 & $\begin{array}{l}3^{\text {rd }} \text { cutset is randomly } \\
\text { changed }\end{array}$ & $\mathrm{Z}_{1}$ & $\mathrm{Z}_{2}$ & $\mathbf{a}_{\mathbf{i 3}}$ & $\mathrm{Z}_{4}$ & $\mathrm{Z}_{5}$ & $\mathrm{Z}_{6}$ & 0 \\
\hline 4 & $\begin{array}{l}4^{\text {th }} \text { cutset is randomly } \\
\text { changed }\end{array}$ & $\mathrm{Z}_{1}$ & $\mathrm{Z}_{2}$ & $\mathrm{Z}_{3}$ & $\mathbf{a}_{\mathbf{i} 4}$ & $\mathrm{Z}_{5}$ & $\mathrm{Z}_{6}$ & 0 \\
\hline 5 & $\begin{array}{l}5^{\text {th }} \text { cutset is randomly } \\
\text { changed }\end{array}$ & $\mathrm{Z}_{1}$ & $\mathrm{Z}_{2}$ & $\mathrm{Z}_{3}$ & $\mathrm{Z}_{4}$ & $\mathbf{a}_{\mathbf{i 5}}$ & $\mathrm{Z}_{6}$ & 0 \\
\hline 6 & $\begin{array}{l}6^{\text {th }} \text { cutset is randomly } \\
\text { changed }\end{array}$ & $\mathrm{Z}_{1}$ & $\mathrm{Z}_{2}$ & $\mathrm{Z}_{3}$ & $\mathrm{Z}_{4}$ & $\mathrm{Z}_{5}$ & $\mathbf{a}_{\mathbf{i 6}}$ & 0 \\
\hline
\end{tabular}

TABLE III. Mutation Process of MDEP TeChNique IN TEChNique 3

\begin{tabular}{|c|c|c|c|c|c|c|c|}
\hline & $\begin{array}{l}\text { Initial cutsets from } \\
\text { graph theory approach }\end{array}$ & $\mathbf{Z}_{1}$ & $\mathbf{Z}_{2}$ & $\ldots$ & $\ldots$ & $\mathbf{Z}_{\mathbf{n}}$ & $Z_{n+1}$ \\
\hline 1 & $\begin{array}{l}1^{\text {st }} \text { cutset is randomly } \\
\text { changed }\end{array}$ & $\mathbf{a}_{\mathrm{il}}$ & $\mathrm{Z}_{2}$ & $\ldots$ & $\ldots$ & $\mathrm{Z}_{\mathrm{n}}$ & $a_{n+1}$ \\
\hline 2 & $\begin{array}{l}2^{\text {nd }} \text { cutset is randomly } \\
\text { changed }\end{array}$ & $\mathrm{Z}_{1}$ & $\mathbf{a}_{\mathrm{i} 2}$ & $\ldots$ & $\ldots$ & $\mathrm{Z}_{\mathrm{n}}$ & $a_{n+1}$ \\
\hline 3 & $\begin{array}{l}3^{\text {rd }} \text { cutset is randomly } \\
\text { changed }\end{array}$ & $\mathrm{Z}_{1}$ & $\mathrm{Z}_{2}$ & $\ldots$ & $\ldots$ & $\mathrm{Z}_{\mathrm{n}}$ & $\mathbf{a}_{\mathbf{n}+1}$ \\
\hline 4 & $\begin{array}{l}4^{\text {th }} \text { cutset is randomly } \\
\text { changed }\end{array}$ & $\mathrm{Z}_{1}$ & $\mathrm{Z}_{2}$ & $\ldots$ & $\ldots$ & $\mathrm{Z}_{\mathrm{n}}$ & $a_{n+1}$ \\
\hline 5 & $\begin{array}{l}5^{\text {th }} \text { cutset is randomly } \\
\text { changed }\end{array}$ & $\mathrm{Z}_{1}$ & $\mathrm{Z}_{2}$ & $\ldots$ & $\ldots$ & $\mathrm{Z}_{\mathrm{n}}$ & $a_{n+1}$ \\
\hline 6 & $\begin{array}{l}6^{\text {th }} \text { cutset is randomly } \\
\text { changed }\end{array}$ & $\mathrm{Z}_{1}$ & $\mathrm{Z}_{2}$ & $\ldots$ & $\ldots$ & $Z_{n}$ & $a_{n+1}$ \\
\hline 7 & $\begin{array}{l}\mathrm{n}^{\text {th }} \text { cutset is randomly } \\
\text { changed }\end{array}$ & $\mathrm{Z}_{1}$ & $\mathrm{Z}_{2}$ & $\ldots$ & $\ldots$ & $\mathbf{a}_{\text {in }}$ & $a_{i n+1}$ \\
\hline 8 & $\begin{array}{l}\mathrm{n}+1^{\text {th }} \text { cutset is randomly } \\
\text { changed }\end{array}$ & $\mathrm{Z}_{1}$ & $\mathrm{Z}_{2}$ & $\ldots$ & $\cdots$ & $\mathrm{Z}_{\mathrm{n}}$ & $a_{i n+1}$ \\
\hline
\end{tabular}


The first islanding solution from the final best solutions, $x_{b}$ is selected as the optimal islanding solution. Load flow analysis is then performed and the power imbalance criterion is checked on each island. In the case of any imbalance is found on any island, the load shedding scheme is executed in order to produce the balanced island. Once the power imbalance criterion is fulfilled, the voltage magnitude at each bus and transmission line power flow at each line is checked and analysed. If the voltage limit or line capacity in any islands is violated, the islanding solution is considered not feasible and the next optimal islanding candidate will be selected for evaluation. The islanding solution is considered an optimal solution if the power imbalance, voltage limit and line capacity are fulfilled.

\section{B. Modified Discrete Particle Swarm Optimization (MDPSO)}

Another modified discrete optimization, namely Modified Discrete Particle Swarm Optimization (MDPSO) is developed to validate the performance of MDEP in determining the optimal islanding solution. The flowchart in Fig. 3 shows the process involved to obtain the optimal islanding solution using the MDPSO technique.

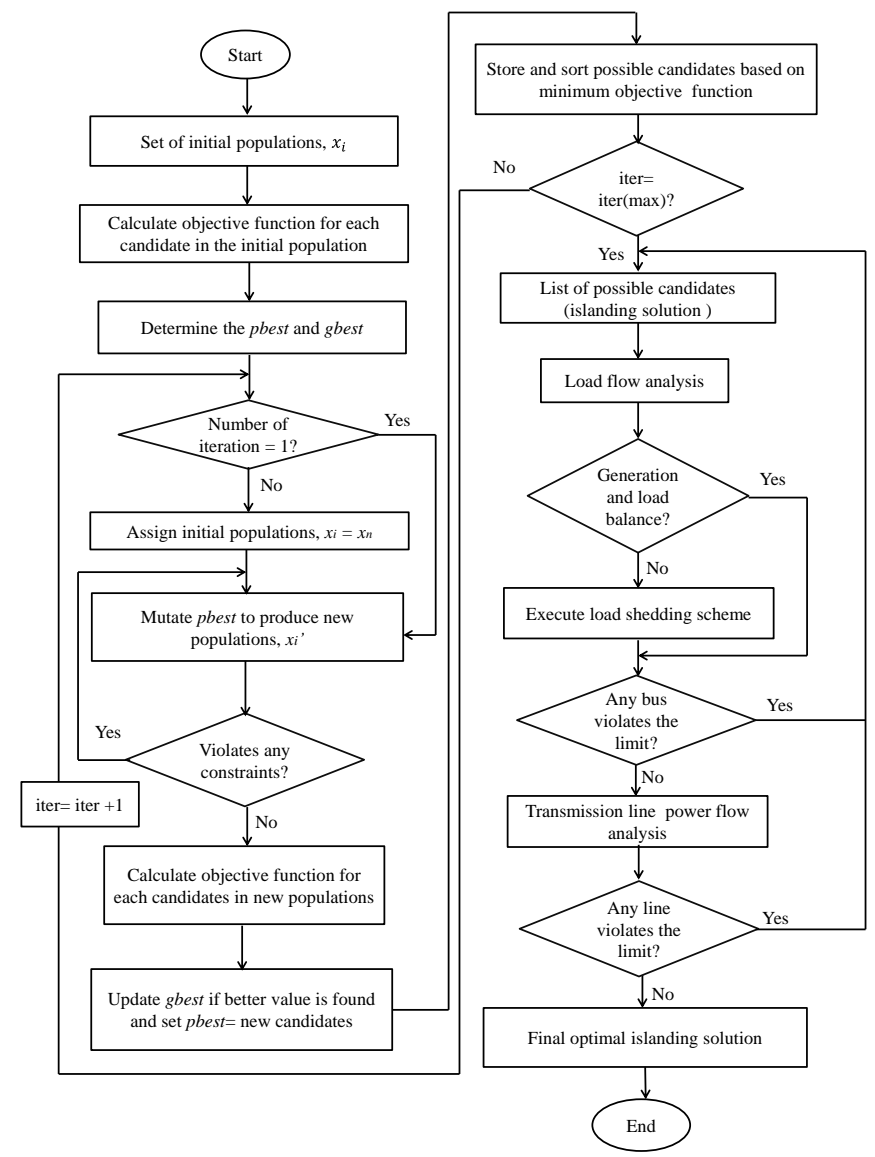

Fig. 3. MDPSO Optimization Technique.

Referring to Fig. 3, the initial solution obtained from the graph theory approach is used as the initial population, $x_{i}$ in the MDPSO technique. Then, the objective function (minimal power flow disruption) is then calculated for each candidate using the equation in (1). The initial pbest and gbest are determined and the mutation process is begun. The similar mutation techniques used in the MDEP technique is utilized in the MDPSO technique to produce new populations, $x_{i}{ }^{\prime}$. Then, the constraints checking process for all the new populations are performed, similar to the MDEP technique. The objective function for each candidate in the new populations is then calculated and stored. The gbest is updated if a better objective function is found and the process continues until it reaches the maximum number of iteration. The new population, $x_{i}$ ' is used as the pbest for each iteration in this technique.

The best possible islanding solution is selected as the optimal islanding solution and load flow analysis is further carried out. Then, the power imbalance (load-generation balance), voltage limits and transmission line capacity are checked and analyzed as performed in the MDEP technique. Finally, the optimal islanding solution which fulfilled these checking criteria is selected as the final optimal islanding solution in this technique.

\section{RESUlt AND ANALYSIS}

The IEEE 118-bus system is used to demonstrate and validates the developed MDEP and MDPSO techniques. This system consists of 19 generators and 186 transmission lines. This work uses the MATLAB R2015a on an Intel ${ }^{\circledR}$ Core $^{\text {TM }}$ i7$5500 \mathrm{U}$ CPU at $2.40 \mathrm{GHz}$ with $8 \mathrm{~GB}$ of RAM is used to code the developed techniques.

\section{A. Case I: IEEE 118-bus System}

In Case I, the controlled islanding is performed by splitting the system into two stand-alone island based on their coherent group of generators, $\mathrm{G}_{1}=\{10,12,25,26,31\}$ and $\mathrm{G}_{2}=$ $\{46,49,54,59,61,65,66,69,80,87,89,100,103,111\}$ [9],[16]. The initial solution obtained using the graph theory approach is shown in Table IV. The initial solution of six cutsets with minimal power flow disruption of $100.164 \mathrm{MW}$ is obtained in this case. Through the utilization of this approach, the huge possible combination of islanding solution $\left(2^{\text {no.of trans. line }}=2^{186} \approx\right.$ $9.808 \times 10^{55}$ ) is reduced to five cutsets as an initial solution.

The initial solution is then used in the MDEP and MDPSO technique to obtain the optimal islanding solution. The results are then compared with other published techniques as illustrated in Table V. It is observed that the MDEP technique provides a better optimal solution with minimal power flow disruption (81.4477 MW) as compared to MDPSO and other published techniques.

TABLE IV. INITIAL SOLUTION FOR CASE I

\begin{tabular}{|l|l|}
\hline Initial Solution & $\sum \mathbf{P}_{\text {disrup }}(\mathbf{M W})$ \\
\hline $19-34,33-37,30-38,24-70,71-72$ & 100.164 \\
\hline
\end{tabular}

TABLE V. COMPARISON OF OPTIMAL ISLANDING SOLUTION - CASE I

\begin{tabular}{|l|l|l|}
\hline Technique & Optimal Islanding Strategy & $\sum \mathbf{P}_{\text {disrup }}(\mathbf{M W})$ \\
\hline $\begin{array}{l}\text { Tabu Search } \\
{[16]}\end{array}$ & $\begin{array}{l}22-23,23-25,23-32,33-37,34-36,34- \\
37,34-43,37-38,38-65\end{array}$ & 890.7296 \\
\hline $\begin{array}{l}\text { Controlled } \\
\text { Islanding [9] }\end{array}$ & $\begin{array}{l}24-70,34-43,38-65,40-41,40 \\
-42,71-72\end{array}$ & 232.7722 \\
\hline MDPSO & $15-33,19-34,30-38,23-24$ & 83.7969 \\
\hline MDEP & $\begin{array}{l}15-33,19-34,30-38,24-70,24- \\
72\end{array}$ & 81.4477 \\
\hline
\end{tabular}


The optimal solution using MDEP technique is used to implement the controlled islanding solution which forms two stand-alone islands and the information of this execution is shown in Table VI.

Referring to Table VI, the total generation, Pgen in both Island 1 and Island 2 are more than the total load demand, Pload. Therefore, the load shedding scheme is not required in both islands. Then, the voltage limit at each bus and power flow at each line are checked for both islands in order to ensure that the voltage limit and power flow capacity is not exceeded after controlled islanding execution.

\section{B. Case II: IEEE 118-bus System}

In Case II, the controlled islanding is performed by splitting the system into three stand- alone island based on their coherent group of generators, $\mathrm{G}_{1}=\{10,12,25,26,31\}, \mathrm{G}_{2}=$ $\{46,49,54,59,61,65,66,69\}$, and $G_{3}=\{80,87,89,100,103,111\}$. The initial solution obtained using the graph theory approach is shown in Table VII.

This initial solution is then used to assist the developed MDEP and MDPSO techniques to determine the optimal islanding solution. The results are then compared with other published techniques as illustrated in Table VIII. It is proved that the MDEP technique provides a better optimal solution with minimal power flow disruption (296.0604 MW) as compared to the MDPSO and other published techniques.

TABLE VI. OPTIMAL INTENTIONAL ISLANDING SOLUTION FOR CASE I

\begin{tabular}{|l|l|l|l|l|}
\hline \multirow{2}{*}{ Islands } & \multirow{2}{*}{ Buses Info } & \multicolumn{2}{|l|}{ Active Power $(\mathbf{M W})$} & $\begin{array}{l}\text { Load } \\
\text { Shed } \\
\text { (MW) }\end{array}$ \\
\cline { 3 - 4 } & & Total Pgen & Total Pload & \\
\hline Island 1 & $1 \sim 32,113 \sim 115,117$ & 1011.153 & 976.0 & - \\
\hline Island 2 & $33 \sim 112,116,118$ & 3363.901 & 43.0 & - \\
\hline
\end{tabular}

TABLE VII. INITIAL SOLUTION FOR CASE II

\begin{tabular}{|l|l|}
\hline Initial Solution & $\sum \mathbf{P}_{\text {disrup }}(\mathbf{M W})$ \\
\hline $19-34,33-37,30-38,24-70,71-72,78-79$, & 314.9342 \\
$77-80,77-80,80-81,77-82$ & \\
\hline
\end{tabular}

TABLE VIII. COMPARISON OF OPTIMAL ISLANDING SOLUTION - CASE II

\begin{tabular}{|l|l|l|}
\hline Technique & Optimal Islanding Strategy & $\sum \mathrm{P}_{\text {disrup }}(\mathrm{MW})$ \\
\hline $\begin{array}{l}\text { Controlled } \\
\text { Islanding [9] }\end{array}$ & $\begin{array}{l}40-41,40-42,34-43,38-65,71-72,24- \\
70,75-77,76-118,69-77,68-81\end{array}$ & 385.8167 \\
\hline MDPSO & $\begin{array}{l}15-33,19-34,30-38,24-70,71-72,78- \\
79,77-80,77-80,68-81,77-82\end{array}$ & 304.6849 \\
\hline MDEP & $\begin{array}{l}15-33,19-34,30-38,24-70,24-72,78- \\
79,77-80,77-80,68-81,77-82\end{array}$ & 226.0604 \\
\hline
\end{tabular}

TABLE IX. OPTIMAL INTENTIONAL ISLANDING SOLUTION FOR CASE II

\begin{tabular}{|l|l|l|l|l|}
\hline \multirow{2}{*}{ slands } & \multirow{2}{*}{ Buses Info } & \multicolumn{2}{|l|}{ Active Power $($ MW) } & $\begin{array}{l}\text { Load } \\
\text { Shed } \\
\text { (MW) }\end{array}$ \\
\cline { 3 - 4 } Island 1 & $\begin{array}{l}1 \sim 32,113 \sim 115, \\
117\end{array}$ & 1011.153 & 976.0 & - \\
\hline Island 2 & $33 \sim 78116,118$ & 2173.212 & 2102.0 & - \\
\hline Island 3 & $79 \sim 112$ & 1192.906 & 1164.0 & - \\
\hline
\end{tabular}

The optimal solution using MDEP technique is used to implement the controlled islanding solution which forms three stand-alone islands and the information of this implementation is shown in Table IX.

Referring to Table IX, the three islands formed in this case are balance in terms of power balance criterion. This is due to the fact that the total generation, Pgen in all three islands; Island 1, Island 2 and Island 3 are more than the total load demand, Pload. Therefore, load shedding scheme is not required in any of these islands. Once the power balance criterion is fulfilled, the voltage limit at each bus and power flow at each line are checked for all islands in order to ensure that the voltage limit and power flow capacity is not exceeded after controlled islanding execution.

\section{CONCLUSION}

This paper investigates two different techniques that developed to determine the optimal islanding solution. The effectiveness of the developed techniques, MDEP and MDPSO are evaluated through case studies using the IEEE 118-bus system. The results proved that the MDEP technique capable on determining the optimal islanding solution with minimum power flow disruption as compared to MDPSO and other published works in Case I and Case II, respectively. As such, MDEP technique is selected as the best technique to implement the controlled islanding action. This research emphasizes on obtaining the optimal islanding solution with lower power flow disruptions, as it helps to improve the transient stability in each island after the implementation of controlled islanding.

In the future study, the implementation of controlled islanding taking into account the severe outages will be investigated and analyzed using the selected MDEP technique.

\section{ACKNOWLEDGMENT}

The author would like to express her appreciation to Ministry of Higher Education Malaysia (MOHE) via FRGS Grant (FRGS/1/2018/TK07/UNITEN/01/1) to fund this research. In addition, the author would like to thank Universiti Teknikal Malaysia Melaka (UTeM) and Universiti Tenaga Nasional (UNITEN) for their support in this research.

\section{REFERENCES}

[1] N. Z. Saharuddin, I. Z. Abidin, H. Mokhlis, and K. Naidu, "Intentional islanding methods as post fault remedial action: A review," Indones. J. Electr. Eng. Comput. Sci., vol. 12, pp. 182-192, 2018.

[2] G. Andersson et al., "Causes of the 2003 Major Grid Blackouts in North America and Europe, and Recommended Means to Improve System Dynamic Performance," IEEE Trans. Power Syst., vol. 20, no. 4, pp. 1922-1928, 2005.

[3] S. Larsson and A. Danell, "The black-out in southern Sweden and eastern Denmark, September 23, 2003," in 2006 IEEE PES Power Systems Conference and Exposition, 2006.

[4] Q. Zhao, K. Sun, D. Zheng, J. Ma, and Q. Lu, "A study of system splitting strategies for island operation of power system: a two-phase method based on OBDDs," IEEE Trans. Power Syst., vol. 18, no. 4, pp. 1556-1565, 2003.

[5] K. Sun, D. Z. Zheng, and Q. Lu, "Splitting strategies for islanding operation of large-scale power systems using OBDD-based methods," IEEE Trans. Power Syst., vol. 18, no. 2, pp. 912-923, 2003.

[6] H. You, V. Vittal, and X. Wang, "Slow Coherency-Based Islanding," IEEE Trans. Power Syst., vol. 19, no. 1, pp. 483-491, 2004. 
[7] X. Wang, S. Member, and V. Vittal, "System Islanding Using Minimal Cutsets with Minimum Net Flow," in Power System Conference and Exposition, 2004, pp. 1-6.

[8] G. Xu, S. Member, and V. Vittal, "Slow Coherency Based Cutset Determination Algorithm for Large Power Systems," IEEE Trans. POWER Syst., vol. 25, no. 2, pp. 877-884, 2010.

[9] J. Q. Tortos and V. Terzija, "Controlled islanding strategy considering power system restoration constraints," IEEE Power Energy Soc. Gen. Meet., pp. 1-8, 2012.

[10] P. A. Trodden, W. A. Bukhsh, A. Grothey, and K. I. M. Mckinnon, "MILP Formulation for Islanding of Power Networks," IEEE Trans. POWER Syst., vol. 29, pp. 1-8, 2014.

[11] P. A. Trodden, W. A. Bukhsh, S. Member, A. Grothey, and K. I. M. Mckinnon, "Optimization-based Islanding of Power Networks using Piecewise Linear AC Power Flow," IEEE Trans. POWER Syst., vol. 29, 2014.

[12] P. Demetriou, A. Kyriacou, E. Kyriakides, and C. Panayiotou, "Applying Exact MILP Formulation for Controlled Islanding of Power Systems," in 51st International Universities Power Engineering Conference (UPEC), 2016.
[13] M. R. Aghamohammadi and A. Shahmohammadi, "Electrical Power and Energy Systems Intentional islanding using a new algorithm based on ant search mechanism," Int. J. Electr. Power Energy Syst., vol. 35, no. 1, pp. 138-147, 2012.

[14] W. Liu, L. Liu, and D. A.Carter, "Binary Particle Swarm Optimization Based Defensive Islanding Of Large Scale Power Systems," Int. J. Comput. Sci. Appl., vol. 4, no. 3, pp. 69-83, 2007.

[15] L. Liu, W. Liu, D. A. Cartes, and I. Chung, "Slow coherency and Angle Modulated Particle Swarm Optimization based islanding of large-scale power systems," Adv. Eng. Informatics, vol. 23, no. 1, pp. 45-56, 2009.

[16] F. Tang, H. Zhou, Q. Wu, H. Qin, J. Jia, and K. Guo, "A Tabu Search Algorithm for the Power SystemIslanding Problem," Energies, vol. 8, no. 10, pp. 11315-11341, 2015.

[17] L. Ding, F. M. Gonzalez-longatt, S. Member, P. Wall, V. Terzija, and S. Member, "Two-Step Spectral Clustering Controlled Islanding Algorithm," IEEE Trans. POWER Syst., vol. 28, no. 1, pp. 75-84, 2013.

[18] N. Saharuddin, I. Zainal Abidin, H. Mokhlis, A. Abdullah, and K. Naidu, "A Power System Network Splitting Strategy Based on Contingency Analysis," Energies, vol. 11, no. 2, p. 434, 2018. 